Jagas, Canibalismo e "Guerra Preta": os Mbangalas, entre o mito europeu e as realidades sociais da África Central do século XVII

Jaga, Cannibalism and the "Guerra Preta": the Mbangalas, between the european myth and the social realities of the Central Africa in the XVII century

José Rivair MACEDO*

Resumo: Os textos europeus do século XVII em geral conferem aos jagas papel determinante como elemento desagregador das populações centro-africanas, qualificando-os de selvagens, canibais e adeptos de práticas de idolatria. O objetivo do presente artigo é apresentar tais pontos de vista a partir do estudo dos rituais atribuídos aos jagas no tratado intitulado Istorica descrizione de tre regni, Congo, Matamba et Angola, de autoria do missionário capuchinho Giovanni Cavazzi de Montecúccolo. Tais rituais serão confrontados com as descrições a respeito do papel que os jagas desempenharam nas guerras do sertão africano durante o processo de conquista do Ndongo.

Palavras-chave: Jagas; Rituais; África Central; Relatos de viajantes.

Abstract:The seventeenth-century European texts generally describe the Jaga role as a disruptive element of the peoples in the central Africa, calling them savages, cannibals and who practice idolatry. This paper presents to such view from the study of the rituals assigned to the Jaga in the Istorica descrizione tre regni, Congo, Matamba et Angola, by capuchin missionary Giovanni Cavazzi of Montecúccolo. Such rituals are faced with the descriptions about the role that Jaga played in the wars of the african hinterland during the conquest of Ndongo.

Keywords: Jagas; Rituals; Central Africa; Traveler's accounts.

\footnotetext{
* Professor Doutor, com atuação na área de História da África no Departamento de História e Programa de Pós-Graduação em História - Instituto de Filosofia e Ciências Humanas da Universidade Federal do Rio Grande do Sul, Campus do Vale - Avenida Bento Gonçalves, 9500, Bloco 3, Agronomia, CEP: 90540-000, Porto Alegre, RS, Brasil. A pesquisa que resultou neste artigo contou com financiamento do CNPQ, a partir de Bolsa de Produtividade em Pesquisa concedida para a realização do projeto "Portugueses e africanos no contexto da abertura do Atlântico". E-mail: jrivair@uol.com.br; jose.rivair@ufrgs.br
} 
A conquista do litoral centro-africano pelos portugueses ocorreu entre os séculos XVI-XVII e foi desencadeada pelos contatos que eles estabeleceram com os povos bakongo, das atuais repúblicas do Congo, e com os povos mbundo, da República Popular de Angola. Os registros dos acontecimentos desse amplo contexto encontram-se espalhados em fontes documentais de diversa procedência, sobretudo em dois relatos bem conhecidos entre os historiadores, escritos na segunda metade do século XVII, a Istorica descrizione de tre regni, Congo, Matamba et Angola, de autoria de Giovanni Antonio Cavazzi de Montecúccolo (1621-1678), e a História Geral das Guerras Angolanas, de autoria de António de Oliveira Cadornega (1623-1690). Tais relatos fornecem ao leitor um amplo quadro das circunstâncias em que se deram a conquista político-militar do reino do Congo e do Ndongo e do primeiro ciclo da ação missionária, visando-se, concomitantemente, à conquista espiritual (OLIVEIRA, 2010; MATTOS, 2011).

\section{Contexto}

Os primeiros contatos se fizeram no que os europeus denominaram de reino do Congo, a partir de relações diplomáticas e comerciais com o aval dos manicongo pertencentes ao clã dos lukeni, que nesse instante viram na aproximação com os portugueses e com o seu modelo de vida uma estratégia de afirmação política junto às demais lideranças locais. No governo de Mvemba-a-Nzinga, mais conhecido pelo nome cristão de Afonso I (c. 1456-1543), o cristianismo passou a ser a religião oficial do reino, com a proibição das religiões tradicionais e do culto aos fetiches - que levou ao movimento conhecido como "Revolta da casa dos ídolos". Inspirando-se no regimento de governo enviado em 1512 pelo monarca português Manuel I, uma série de modificações internas foi introduzida no Congo, com a difusão de títulos de nobreza e o empréstimo de símbolos de poder de proveniência europeia. ${ }^{1}$

Envolvido em conflitos internos que se sucederam à morte de Afonso I, o reino do Congo sofreria forte abalo em 1568, quando suas populações foram atacadas e parcialmente massacradas por um grupo nômade de guerreiros que ficaram notabilizados pelo nome de jagas. Para fazer face a eles, o Congo necessitou da ajuda de tropas europeias e suas armas de fogo, e, depois de passada a tormenta das invasões, aumentou a pressão dos traficantes de escravos luso-africanos sediados na Ilha de São Tomé e dos representantes da monarquia lusa. Nas primeiras décadas do século XVII, 
os manicongos tentaram se aproximar de outras nações europeias, como a França, Roma e os Estados italianos, inclusive a Holanda, para contrabalançar a influência dos portugueses em suas áreas de influência (VANSINA, 1965, p. 100-110; RANDLESS, 1968, p. 129-134). No momento em que Cavazzi de Montecúccolo redigia sua obra, o Congo estava bastante debilitado após a derrota frente aos portugueses na batalha de Mbwila, ocorrida em 1665, enquanto outros centros de poder africanos ganhavam maior projeção no interior, entre eles, os reinos de Matamba e de Kasanje (THORNTON, 1982, p. 330).

Mais para o Sul, no Ndongo, os contatos com os europeus também não foram tranquilos, marcados por constantes conflitos político-militares com os principais governantes, os ngola. A primeira investida, de 1520-1526, falhou e foi socorrida pelo manicongo Afonso I; o mesmo ocorreu com a campanha de 1560-1564. Em 1571, com a concordância do manicongo Álvaro I (1568-1648), o militar Paulo Dias de Novais e suas tropas adentraram o território mbundo, fixando sua base inicial de operações na fortaleza de São Paulo de Luanda, fundada em 1576. Articulando uma política de negociação com os chefes tradicionais das unidades políticas menores, os sobas, de imposição militar aos adversários dos interesses portugueses e de expansão do catolicismo por meio da atividade missionária jesuítica, carmelita e capuchinha, os europeus foram aos poucos incorporando o Ndongo, com os sobas reduzidos à condição de vassalagem e sujeitos ao pagamento de tributos, situação que assinala o ponto de partida da posterior província de Angola (BIRMINGHAM, 1974). ${ }^{2}$

$\mathrm{O}$ acirramento do conflito com os portugueses foi motivado pela disputa e controle das minas de prata do Cambembe, das minas de sal de Kissama e das minas de cobre de Benguela, além, principalmente, do controle do tráfico de escravos. A conquista efetiva do território do Ndongo ocorreu na primeira metade do século XVII, com a intensificação dos conflitos entre 1605-1641, período em que os portugueses tiveram maior sucesso nas investidas no território mbundo, enfraquecendo a autoridade dos ngola (HEINTZE, 1981). Finalmente, na última fase das guerras angolanas, de 1641 a 1663, a disputa envolveu a interferência de concorrentes europeus, os holandeses, e a articulação da resistência militar na figura carismática de Nzinga Mbandi (1581-1663), governanta, primeiro do Ndongo e depois de Matamba (CURTO, 2008). Foi durante esse período que as autoridades africanas solicitaram cada vez mais a interferência da Igreja romana, com o envio de missionários desvinculados dos interesses lusos, pelo que houve a remessa, entre 1645-1665, de um grande contingente de capuchinhos ao 
Jagas, Canibalismo e "Guerra Preta": os Mbangalas, entre o mito europeu e as realidades sociais da África Central do século XVII

Congo e ao Ndongo, do qual Giovanni Cavazzi de Montecúccolo era parte integrante (RICARD, 1958; RANDLESS, 1968, p. 225).

\section{Jagas e Canibalismo}

O relato de Cavazzi de Montecúccolo provém da experiência pessoal acumulada durante os treze anos em que o escritor permaneceu na África central (1654-1667), de dados recolhidos entre os demais missionários e informantes locais, de pesquisa documental em cartas de religiosos, autoridades congolesas e portuguesas, além da consulta a textos normativos e narrativos anteriores. Assim, o que se tem é parcialmente o olhar de um narrador-participante e parcialmente a obra de um erudito e pesquisador.

Para alguns investigadores atuais, como Mariana Bracks Fonseca, durante a maior parte do tempo em que esteve na África ele teria permanecido em Mpungo-aNdongo, onde governava o maior adversário de Nzinga Mbandi, chamado Ngola Are, de onde vem a provável influência de informações negativas sobre ela e sobre os jagas (FONSECA, 2012, p. 16). Já na opinião de Mario Albano, logo depois de uma breve passagem por Luanda ele teria se dirigido ao reino de Matamba e se tornado amigo pessoal de Nzinga, atuando diretamente para sua segunda conversão ao catolicismo, em 1657, como seu confessor e conselheiro, inclusive, representando-a em missões diplomáticas junto aos portugueses e certas autoridades africanas por volta de 1660 (ALBANO, 2012).

O certo é que a maior ou menor proximidade física com os africanos não afetou os pontos de vista do missionário, que, de modo geral, mantém uma posição eminentemente eurocêntrica na descrição e um tom de crítica e de desconfiança em face das instituições e do modo de vida das populações a quem lhe foi confiada a difícil tarefa de promover a conversão religiosa. Não faltam no texto palavras ásperas de desaprovação da poligamia e das formas de idolatria que persistiam no culto aos espíritos ancestrais (MONTECÚCCOLO, 1965, I, p. 93). Diante de um quadro cultural, social e político distinto do modelo cristão-europeu, como os demais evangelizadores ele reagiu pela negação, fechando-se em seus próprios referenciais e negando valor social às formas de organização das populações centro-africanas (GONÇALVES, 2008, p. 116-127). Ao condenar a poligamia, o concubinato e o que pensava ser "sexo livre", por exemplo, seu olhar não ia além da superfície do tecido social, incapaz de discernir as formas particulares de relações de parentesco, baseadas na sucessão de linhagens 
matrilineares e matrilocais, ou matrilineares e patrilocais (ALMEIDA, 1997, p. 155164).

Este posicionamento reproduz, de certo modo, as condições pelas quais o cristianismo foi implantado em domínio bakongo e mbundo. Embora a difusão do catolicismo no Congo e no Ndongo remontasse ao início do século XVI, sua irradiação não promoveu o desaparecimento das crenças ancestrais nativas, mas em parte se superpôs, em parte as absorveu e em parte se fundiu a elas, o que se pode verificar na persistência de elementos rotulados negativamente como "idolatria" e "superstição". De fato, a adoção do cristianismo pelos centro-africanos não foi imediata nem isenta de interesses de ambas as partes envolvidas no processo de conversão: a assimilação dos elementos cristãos feita por intermédio das línguas nativas criava fusões e associações entre o cristianismo e o universo mágico-religioso dos congoleses, "num jogo especular que tendia a preservar, sob verniz cristão, antigas práticas religiosas e culturais" (NSONDÉ, 1992, p. 710; NSONDÉ, 1995).

Todo o texto de Cavazzi de Montecúccolo é atravessado pelas ideias gerais que deram forma, desde a Idade Média, ao discurso cristão, baseado no binômio cristianismo/civilização em oposição ao binômio paganismo/selvageria (WOORTMANN, 2005; HORTA, 1991, p. 95-96). A única alternativa considerada razoável aos africanos seria a adoção da "verdade", representada pela religião cristã. Ele tinha ciência, entretanto, de que esta não era mais do que uma fina camada de verniz sobreposta aos traços sociais originais das populações em processo de conversão e de que a maior predisposição para a adoção do cristianismo encontrava-se entre as populações do litoral, das margens dos rios navegáveis, ou de cidades. Sobre esta suposta propensão das populações litorâneas ao cristianismo, propõe a seguinte explicação: "lidando com os portugueses ou com outros europeus, são iluminados pela luz da civilização e por noções mais humanas e mais razoáveis" (MONTECÚCCOLO, 1965, I, p. 86). As regiões afastadas, do interior, de acordo com seu raciocínio, estariam mais "contagiadas", mais dominadas pelos antigos mestres e costumes, entregues às mais grosseiras formas de selvageria, e os jagas constituem o melhor exemplo de um povo selvagem pouco afeito aos benefícios da civilização cristã, como se pode ver na descrição geral que ele apresenta desses povos:

É uma gente de cuja boca sai continuamente a mentira e a falsidade, sempre dada ao roubo e a qualquer crime. É um povo sempre sedento 
de sangue e de carnificina, ávido devorador de carne humana, feroz contra as feras, cruel para com os inimigos e até contra os próprios filhos. Numa palavra: parece animado por sentimentos tão maus que o inferno nunca vomitou fúrias e tiranos que possam servir de comparação (MONTECÚCCOLO, 1965, I, p. 175).

Impressiona a quantidade de qualificativos negativos em trecho tão curto, em que os jagas são associados ao crime, falsidade e violência desmedida, sem qualquer controle dos apetites e dos instintos, enfim, a comportamentos e atitudes típicos dos povos selvagens. É a essa noção europeia de "selvageria" que se deve vincular o desenvolvimento de um topos recorrente nos textos de europeus dos séculos XVI-XVII que estiveram no Congo e Ndongo - o dos jagas como um povo canibal. Cavazzi de Montecúccolo reproduz esse topos procurando explicar, a partir dos instrumentos conceituais que sua formação cristã lhe permitia, o lugar dos jagas na classificação do mundo cristão como uma "seita" e descrevendo detalhadamente aquilo que lhe parecia constituir os traços distintivos do grupo: a prática do infanticídio, dos sacrifícios humanos e do canibalismo.

Percebendo tratar-se de grupos migrantes, inicia a descrição pela identificação da área de dispersão dos jagas e oferece duas possibilidades de interpretação. Eles poderiam ter começado sua devastadora migração num local qualquer do território denominado Mwene-Muji, perto das nascentes dos rios Nilo e Zaire, ou proviriam das montanhas de Serra Leoa. Teriam sido conduzidos no princípio por um guerreiro denominado Zimbo, e depois pela mulher Temba Ndumba, percorrendo várias localidades até penetrarem e atacarem o reino do congo:

Devastando todo o reino e aumentadas as suas fileiras com os vencidos, que não tinham outra alternativa para não serem mortos, os jagas saíram, inundando os países limítrofes com um mar de sangue, e penetraram na Abissínia, que está situada no lado oposto da África (MONTECÚCCOLO, 1965, I, p. 175).

Ao teorizar sobre a origem dos jagas, tem-se então uma explicação generalizante que lhes confere posição de centralidade como elemento desagregador em diferentes áreas do continente africano, da Abissínia ao Congo, com ataques e massacres no litoral oriental, na fortaleza portuguesa de Tete e nas antigas cidades de Mombaça, Quíloa e Melinde. Essas informações se articulam com as dos cronistas do século XVII, como o português João dos Santos, em sua Ethiopia Oriental, publicada em 1609, que relata em 
tom dramático as incursões dos ferozes canibais denominados zimba em diversas comunidades próximas ao Zimbabwe no ano de 1592 (ALINA, 2011). Tais relatos estimularam o surgimento de uma espécie de história-catástrofe, admitida acriticamente pela erudição europeia até o início do século XX, quando se pensava em sucessivas invasões "bárbaras" de jagas, galas, manes e zimbas desde 1491 até 1510, isto é, no tempo dos primeiros contatos com os europeus (AVELOT, 1912).

O resultado foi o reforço do mito dos povos canibais da África equatorial e tropical, que já se encontrava disseminado em textos de autores muçulmanos anteriores ao século XVI, como al-Idrisi, al-Masudi e Ibn Battuta (CUOCQ, 1974, p. 137; 203; 283; 313), e ganhou força no discurso europeu, particularmente em relação aos galas da Abissinia, aos manes de Serra Leoa, os fang do Gabão e os Azande (niam niam) (HEINTZE, 2006; HENRIQUES, 2004). No período colonial, a imputação do canibalismo acabou sendo generalizada e, no caso de grupos que praticaram a antropofagia, a explicação desconsiderou seu caráter ritualístico e cerimonial, despojando-a de qualquer carga simbólica e reduzindo-a a mero apetite alimentar (CORREA, 2008; CABRAL, 2007).

Registros deixados por escritores europeus anteriores a Cavazzi de Montecúccolo confirmam o teor dramático que acompanha o tema das incursões dos jagas no reino do Congo. Para Filipo Pigafetta, em sua Relação do Reino do Congo, redigida a partir do depoimento pessoal do mercador português Duarte Lopes, em 1591, aqueles nômades provenientes das áreas próximas às nascentes do Nilo era "gente cruel e homicida, de grande estatura e de semblante terrível, nutrindo-se de carne humana" (LOPES/PIGAFETTA, 1951, p. 111-112). Sua invasão em 1568 aos domínios do Congo teria causado profunda devastação do reino, desorganizando-o e gerando situação de dificuldade generalizada, o que forçou o manicongo Álvaro I a pedir ajuda à monarquia portuguesa, no que foi atendido com o envio de uma tropa armada de 600 homens a serviço de Francisco Gouveia, que retornou à península Ibérica em 1574 (PINTO, 2000, p. 215). Algum tempo depois, em 1601, o aventureiro inglês Andrew Battell, enviado pelos portugueses até o Planalto de Bengüela, permaneceu entre os jagas cerca de quatro meses, participou de suas guerras e descreveu o caráter marcial do grupo, suas instituições e seus monumentos, dos quais o principal situava-se no centro da comunidade e se chamava Quesango: em torno dele estavam os crânios dos vencidos ali sacrificados junto com sangue de animais e óleo de palma (RAVENSTEIN, 1910, p. $33)$. 


\section{Jagas, Canibalismo e "Guerra Preta": os Mbangalas, entre o mito europeu e as realidades}

sociais da África Central do século XVII

Em meados da década de 1970, os elementos estruturantes do "mito jaga", inaugurado por Pigafetta e reproduzido pelos escritores do século XVII, por eruditos e historiadores posteriores, foram motivo de uma discussão acadêmica aberta pelos especialistas norte-americanos Joseph Miller e John Thornton. Para o primeiro, as “invasões jagas" não tiveram existência histórica, mas resultariam de uma invenção dos escritores europeus, missionários, traficantes de escravos e funcionários da coroa portuguesa. O ataque a Mbanza Congo em 1568 não teria sido obra de inimigos externos, mas de adversários oriundos da província de Mbata insatisfeitos com a ascensão de Álvaro I ao governo do Congo (MILLER, 1973). Reagindo a essa interpretação, Thornton insistiu na condição estrangeira dos atacantes, que teriam partido da região do Kwango, situada ao leste e habitada atualmente pelos Yaka (THORNTON, 1978). Algum tempo depois, outro especialista, o belga François Bontik, se pronunciou a respeito, tomando o partido de Miller. Em sua opinião, o contexto em que se deram os ataques à sede do governo do manicongo confirmaria a existência de uma animosidade crescente dos chefes de Mbata após a mudança das regras de sucessão por ocasião da morte de Afonso I, em 1545, que se teria agravado nos governos de Diogo (1545-1561), Henrique (1567-1568) e explodido no momento da ascensão de Álvaro I (1568-1587) (BONTIK, 1980).

O debate teve continuidade com as pesquisas de Anne Hilton, para quem a invasão jaga deveria ser reintroduzida no contexto histórico africano. Em suas palavras, jaga era um designativo cuja acepção não se vinculava a uma identidade étnica particular, mas tinha sua raiz etimológica no vocábulo $a k a$, que designava simplesmente o "outro", isto é, o "estrangeiro", o "atacante", o "salteador". Podia ser aplicado a diferentes grupos de forasteiros no Congo, como os povos Tio do norte do Zaire, os Mbangalas, e os "Majaca", que migraram do leste e parecem ter sido os atacantes de Mbanza Congo em 1568, a partir de Mbata (HILTON, 1981). Esta interpretação se impôs entre os historiadores, e mais recentemente Paulo Souza Pinto apresentou fontes documentais até agora desconsideradas no debate, como a História de São Domingos de Frei Luís de Cácegas e Frei Luís de Souza, editada em 1622, e, sobretudo, o relato inédito de João Ribeiro Gaio, que participou de uma missão no Congo em 1588 e se lembra do apoio militar prestado por Francisco de Gouveia "contra os Iagas que eram homens que comiam carne humana" (PINTO, 2000, p. 211).

Embora a posição de Miller sobre a historicidade da invasão jaga de 1568 tenha sido superada, parece-nos que algumas considerações feitas por ele não devem ser 
descartadas. Devido à elasticidade na aplicação do designativo, o termo jaga foi utilizado de modo recorrente nas fontes primárias do século XVII para designar povos de natureza diversa, e as ideias de ferocidade, selvageria e canibalismo foram utilizadas de modo recorrente pelos europeus, de acordo com seus interesses. Desde o início do século XVII, quando as divergências com o Congo aumentaram, o apoio militar enviado pelos portugueses passou a ser gradualmente lembrado pelos governadores de Angola em momentos em que se reivindicava certa ascendência em relação aos manicongos. ${ }^{3}$ Quanto ao texto dos missionários, as acusações contra os jagas assumiam tom grandiloquente, associadas a práticas "supersticiosas" e de idolatria e destacadas do sentido original das práticas sociais das populações centro-africanas. A primeira medida tomada por Serafim de Cortona e Antonio Romano, os freis capuchinhos que rebatizaram a Rainha Nzinga, foi proibir o "rito dos jagas", que consistia, segundo eles, em: 1) não criar filhos, mas expor os recém-nascidos às feras ou enterrarem-nos vivos; 2) adotar como filhos os jovens aprisionados em guerra, "tirando-lhes dois dentes dianteiros"; 3) comer carne humana; 4) render sacrifícios humanos aos antepassados; 5) adorar ídolos e outras superstições (ANGUIANO, 1957, v. 2, p. 14; BRÁSIO, v. 12, p. 199).

A essa imagem carregada de cores fortes, com grande tendência a exotização, devem-se acrescentar os qualificativos e caracterizações atribuídos à figura emblemática da Rainha Nzinga Mbandi devido à sua expressiva liderança contra os portugueses nas décadas de 1620-1660. Ao abandonar o Ndongo e se deslocar ao reino de Matamba, ela teria adotado a "lei dos jagas", mencionadas no parágrafo anterior, implantando-as na organização de um kilombo ${ }^{4}$. A excepcionalidade de sua liderança chamou a atenção já dos contemporâneos, que projetaram nela um conjunto de imagens estereotipadas. Numa obra de autoria anônima escrita em 1663, consta que ela se vestia com trajes masculinos e exigia ser chamada de "rei", que ao comer carne humana apreciava sobremaneira as partes dos seios femininos e o coração; que era servida por trezentos jovens de ambos os sexos, divididos em seis grupos, vestidos com trajes do sexo oposto e que praticavam o sexo livre (BRÁSIO, v. 12, p. 469-472). Noutro relato, do belga Barthélemy d'Espinchal, redigido em 1667, a essas "aberrações" é acrescentada a informação de que seus guerreiros mais bravos combatiam com as tripas secas de adversários anteriores que já tinham sido devorados amarradas ao pescoço, comendo-as antes do início da batalha para melhor incutir pavor entre os combatentes da outra parte (BRÁSIO, v. 11, p. 254-255). 


\section{Jagas, Canibalismo e "Guerra Preta": os Mbangalas, entre o mito europeu e as realidades sociais da Africa Central do século XVII}

Foram imagens como essas que, em conjunto, reforçaram o mito do "jaga canibal" e produziram o estereótipo de uma "rainha Jinga" depravada e desprovida de humanidade. O reforço delas beneficiou os capuchinhos, que souberam explorar ad nauseam o feito de reintegrar aquela governante, junto com seu povo "selvagem", aos padrões do mundo cristão. A cena em que Nzinga declara publicamente abandonar os "ritos gentílicos" e adota o casamento monogâmico, símbolo maior do enquadramento aos valores do mundo cristão, foi exaustivamente noticiada na época (BRÁSIO, v. 12, p. 94; 101-102; 199), mas os aspectos exóticos de seu comportamento anterior à conversão continuaram a alimentar a imaginação europeia no século das luzes, e mesmo na contemporaneidade (MATA, 2012).

\section{Mbangalas e "Guerra Preta"}

Deixando de lado os estereótipos, haveria indício na documentação não narrativa a confirmar o propalado canibalismo dos jagas? As indicações relativas ao grupo em correspondências e relatórios de caráter administrativo produzidas no Congo e em Angola são bem menos enfáticas do que as narrativas até aqui consideradas e sugerem a possibilidade de que o termo designativo "jaga" estivesse cercado de elementos retóricos amplamente compartilhados, mas sem evidências fáticas que pudessem comprovar o consumo de carne humana para fins alimentares. O que essas evidências facilmente comprovam é que, desde as primeiras décadas do século XVII, os portugueses empregaram diversos grupos de “jagas" em suas forças de combate auxiliares na luta contra os exércitos do Ndongo e do Congo, naquilo que aparece descrito nas fontes como a "guerra preta".

Considerando apenas as alusões feitas por autoridades africanas, verifica-se que a descrição dos jagas aparece rodeada de qualificativos negativos, e sua ação, como devastadora. Nas reiteradas reclamações junto ao papado contra a gradual interferência dos governadores de Angola nos negócios do Congo, Álvaro III diz em 26/02/1622 que, com o apoio dos jagas, os portugueses estavam a invadir suas terras (BRÁSIO, v. 7, p. 4). Logo depois, seu sucessor, Pedro II, fazendo referência à Batalha de Mbundi, na qual os portugueses, apoiados por um grande contingente de jagas, atacaram a província de Mbamba, afirma que estes últimos, "devoradores de carne humana”, teriam destruído e provocado desolação no reino, e que inúmeros cristãos teriam sido comidos por eles, entre os quais o Duque de Mbamba, o Marquês de Pemba e outros fidalgos (BRÁSIO, 
v. 7, p. 161). Em outra correspondência, escrita por um cônego anônimo do Congo, repete-se a informação da "grandíssima matança" perpetrada pelos jagas contra os aliados do rei do Congo, "sepultando a todos em os ventres dos bárbaros jagas" (BRÁSIO, v. 7, p. 294).

Do lado português, as referências mostram-se ambíguas. Nas situações em que se pretendia pedir ajuda militar ou apoio financeiro aos monarcas ibéricos, evocavam-se os riscos e perigos dos sertões africanos, entre eles, o do canibalismo. Em 1612, André Velho da Fonseca informava que os contatos com os mercadores negros através de Matamba, de Tumda, e de partes mais remotas se fazia por terras de inimigos, "antre os quais a mayor parte come carne umana de ordinário" (BRÁSIO, v. 6, p. 65). Uma década depois, o Governador Manuel Cerveira Pereira, com a intenção de sensibilizar as autoridades de Lisboa e angariar adeptos para seu projeto de tomar sob controle as áreas das minas de cobre de Benguela, lamentava-se da pouca munição de que dispunha e da falta de homens de guerra: "pellos poucos que aqui estamos e per remate o perdemonos todos et nos comer o gentio da terra et assi lhe encampo" (BRÁSIO, v. 6, p. 444).

A antropofagia é aqui utilizada mais como argumento retórico do que como uma prática comprovada, uma vez que em nenhuma circunstância casos precisos de consumo de carne humana são mencionados ou cenas desse tipo são descritas. Quem parece sintetizar melhor o ponto de vista português a respeito dos jagas é o militar Baltasar Rebelo de Aragão, em seu relatório sobre o andamento das coisas em Angola. Para ele, os iacas seriam uma gente forasteira "que vive de roubar e fazer guerra", organizados em "quadrilhas" sob a chefia de "capitães", noutros termos, grupos de guerreiros seminômades. Em nenhuma circunstância lhes é atribuída a prática do infanticídio, do canibalismo ou dos sacrifícios humanos, mas por sua ferocidade na guerra convinha têlos como aliados para manter os sobas - quer dizer, os chefes locais mbundo - sob controle:

Esta gente é bom tê-los por amigos, porque com temor deles obedecem e estão quietos os sovas, mas de presente se quis apertar tanto com eles que se levantaram e levaram muitos escravos nossos captivos; creio que serão maus de reduzir à nossa amizade, pela ruim companhia que lhe fazemos, estando debaixo de nosso amparo, mas pode-se adquirir outros para amigos e tratá-los bem (CORDEIRO, 1935 , v. 1, p. 233). 


\section{Jagas, Canibalismo e "Guerra Preta": os Mbangalas, entre o mito europeu e as realidades sociais da África Central do século XVII}

A avaliação de Baltasar Rebelo de Aragão toca num ponto crucial para se entender o papel atribuído aos jagas na conquista do Ndongo. Sua aliança com os portugueses garantia a submissão dos sobas, mas o estreitamento das relações levou a que se rebelassem, tomando para si parte dos cativos de guerra. Revela-se aqui outra função desempenhada pelos jagas: a caça e aprisionamento de cativos, no lucrativo negócio do tráfico de escravos. Ao que parece, no início lhes cabia a posição de auxiliares, mas depois passaram a assumir por conta própria as atividades de predação, tornando-se concorrentes dos traficantes.

A documentação portuguesa registra amplamente o envolvimento dos jagas em conflitos, algumas vezes como aliados e outras como inimigos. Em 1621, um oficial militar enumera entre suas primeiras medidas tomadas em Angola a pacificação de Luanda contra os ataques recorrentes de Kasanje, um poderoso chefe guerreiro jaga que tinha sob sua autoridade 16 outros chefes do interior (BRÁSIO, v. 7, p. 17-18). Numa mesma fonte de informação, como o relato de Manoel Pereira a respeito das lutas pela influência na região das minas de cobre de Benguela, entre 1627-1629, há registro de ataques a alguns kilombos, entre eles o do jaga Anguri, que saqueava e pilhava a região de Peringue e Maniberro, "roubando gado e mulheres". Mas no ataque aos soba de Cambembe, investiram 75 soldados portugueses e algo em torno de 1500 negros mbundos e jagas (FELNER, 1933, p. 568-569).

$\mathrm{O}$ recurso constante propiciado aos efetivos guerreiros jagas pelos portugueses transparece na documentação produzida durante o governo de Fernão de Souza (16251630), que corresponde ao período inicial da derrubada de poder das lideranças tradicionais do Ndongo (FONSECA, 2010, p. 398-406; DIAS, 1985). Dos conflitos militares, a "guerra preta", contou com a participação efetiva e determinante de bandos de jagas liderados por Zenza Rugumbe, Kwanza, Gunza, Gumby Ilyamgumbe, Quinda. Dois aliados importantes dos portugueses foram Kabuku ka Ndonga e sobretudo João Kasanje, que acabou beneficiado com a concessão de áreas de influência pela monarquia portuguesa, conhecidas na posteridade como reinado de Kasanje ou jagado de Kasanje (VELLUT, 1975).

Os jagas integravam, pois, inúmeros microestados altamente militarizados, sob a liderança de chefes autônomos que podiam atuar por conta própria ou se aliar, de acordo com sua conveniência em relação aos portugueses ou adversários dos portugueses. A estrutura dessas comunidades, designadas pelo termo genérico de kilombo, foi posta a serviço das empreitadas lusas no sertão, e sua utilização estava especificada claramente 
no regimento do governo local. A maneira pela qual tal "máquina de guerra" atuava aparece descrita no extenso relatório de Fernão de Souza a seus filhos, em que consta que:

Por hum auto que se fez no kilombo, por mandado do capitão mor Bento Banha Cardoso, aos oito dias do mes de março de seiscentos e vinte e sete na Lucanda junto a Lugala, se assentou com o parecer dos capitães que visto estar a guerra junta, e yrse ajuntando, se não perdesse a occasião de marchar, e yr buscar io inimigo e tomar sitio, aonde a gente branca, e preta possa comer e não fuja, e se torne a desfazer o quilombo, e obrigue aos inimigos a pagar o tributo a sua magestade (HEINTZE, 1985, p. 285).

Da citação, convém reter a passagem em que, nas indicações sobre os desdobramentos da ação militar de sítio, se diz "aonde a gente branca, e preta possa comer e não fuja". Haveria aí uma alusão à prática da antropofagia pela "gente preta" logo depois dos ataques? O certo é que a participação dos jagas não era vista com bons olhos por todos os europeus, de modo que, num relatório anônimo a respeito das guerras de Angola escrito em agosto de 1630, propõe-se como legítima a guerra contra aquela gente ímpia, feroz e diabólica, que não lavrava ou semeava, entregue à guerra, ao aprisionamento dos vencidos para parcialmente comê-los em verdadeiros "açougues públicos de carne humana" e parcialmente vendê-los como escravos. Vagantes, destruidores e sem palavra, os jagas seriam, em última instância, bandos de perfeitos traidores (HEINTZE, 1985, p. 212).

É provável que essa posição tão desfavorável dos jagas esteja relacionada com a ascensão da liderança de Nzinga Mbandi, o que a colocou em posição de destaque na disputa pelo controle do Ndongo e como adversária maior dos interesses portugueses. De fato, duas ideias merecem um pouco mais de atenção: primeiro, a relação entre "açougues públicos de carne humana" e comércio de escravos; e a expressão "traidores". Parece tratar-se da mesma ideia formulada por Baltasar Rebelo de Aragão, de que a maior proximidade dos portugueses com os jagas nas ações de apresamento de cativos levou a que estes gradualmente assumissem o negócio individualmente, apropriando-se de parte dos cativos.

Quanto à vinculação de Nzinga Mbandi com os jagas, é preciso tomar certo cuidado para não reproduzir a visão estereotipada europeia. Primeiro, porque ela não era de origem jaga, mas provinha da linhagem dos ngola a kiluanje, portanto, pertencia ao grupo mbundo. Depois, porque não era a única liderança na resistência político-militar 


\section{Jagas, Canibalismo e "Guerra Preta": os Mbangalas, entre o mito europeu e as realidades sociais da Africa Central do século XVII}

ao avanço dos portugueses; nem os jagas, que veio a liderar, foram os únicos a lhes fazer frente. Sua liderança ocorreu justamente num momento de dispersão dos kilombos pelo território do Ndongo e do Congo e se deu paralelamente à de outros chefes locais importantes, como Kafushe Kambari de Quissama e o jaga Kalandula, com quem se aliou em certo momento. Ao implantar em Matamba a estrutura militar de um kilombo, com adoção do modo de vida jaga e do título de tembanza, isto é, de governanta, ela procurou reforçar sua posição mediante o "casamento", ou seja, a ligação efetiva com outros importantes líderes jagas - primeiro, Kasa, e depois, Kasanje (PINTO, 2000, p. 232; FONSECA, 2012, p. 138-146).

Convém ainda considerar as proposições de Joseph Miller, para quem a ideia do apetite voraz dos jagas serviu de desculpa aos traficantes de escravos que, para burlar o pagamento dos tributos devidos à coroa, argumentavam que suas "peças" tinham sido comidas pelos canibais. Aqui, o "mito jaga" desempenhava outra função, a de válvula de escape para os interesses privados do rico tráfico de cativos (MILLER, 1973, p. 133134). Acentuava, por sua vez, a reputação dos incômodos aliados africanos. Num dos mais expressivos testemunhos da conquista político-militar de Angola, António de Oliveira Cadornega sintetiza passo a passo as etapas do longo conflito, indicando em diversas passagens batalhas sangrentas em que os jagas tomaram parte, sem jamais descrever cenas de antropofagia (DEMARET, 2011), mas logo no início da obra, como a reproduzir um lugar-comum já consolidado em 1690, quando redigiu o texto, apresentou o comércio de escravos como um beneficio a inúmeros centro-africanos que, de outro modo, poderiam ser devorados pelos jagas:

Pelo uso que professavam em comerem carne humana que era o seu mais regalado sustento, de que ainda tem por costume os que dahi procedem, de que he composto o quilombo da Rainha Ginga e de Cabucu e o quilombo de Casanji, potentado grande, que tem dominado pello sertão dentro muitas províncias e naçoens de diversas línguas com quem fazem os portugueses resgate de peças que servem de utilidade ao comércio, e muito mais ao serviço de Deos, e bem daquellas almas; por que com estes resgates se evitam a não haver tantos açougues de carne humana, e instruídos na fé de Nosso Senhor Jesus Cristo hindo bautizados e catequizados se embarcão para as partes do Brasil ou pra as outras que tem uso catholico tirados da gentilidade e redimindo-lhes as vidas com que se faz serviço a Deos e bem ao commercio (CADORNEGA, 1972, v. 1, p. 14) .

\section{Rituais do Kilombo}


Temos agora como voltar ao texto de Cavazzi de Montecúccolo e analisá-lo em outros termos, partindo de uma crítica da própria noção dos jagas como um grupo étnico particular e considerando o topos do "jaga canibal" uma construção do discurso dos conquistadores europeus. Essa revisão conceitual passou a ser possível após a publicação, em 1976, da tese de Joseph Miller, que recoloca em outros termos o estudo das formações sociais e estatais da área mbundo nos séculos XVI-XVII ao articular os dados da documentação escrita europeia com o aporte dos tradicionalistas e das tradições orais recolhidas das genealogias, os musendo, e dos episódios narrativos chamados malunda. A introdução desse riquíssimo material, recolhido parcialmente nos séculos XVII, XIX e XX, possibilitou uma releitura das dinâmicas históricas a partir das transformações operadas nas e sobre as instituições propriamente africanas, em que atuaram fenômenos sociais endógenos e exógenos (MILLER, 1995, esp. p. 149-218).

Assim, em vez do "mito dos jagas", deve-se considerar o papel histórico original, e radical, de um vasto grupo de povos denominados coletivamente mbangalas, provenientes de áreas periféricas do Império Luba, em território Lunda, que num tempo anterior ao século XVII teria iniciado uma lenta e devastadora expansão militar através da área dos povos cokwe e ovimbundo e do sudeste da área mbundo, pelo sul do rio Kwanza, dispersando-se a seguir rumo ao norte e ao centro nos domínios do Ndongo, do Congo e de Matamba. A ruptura com suas linhagens de origem implicou o abandono de formas tradicionais de organização social, estruturadas em relações familiares de descendência matrilinear, e a adoção de instituições transversais vinculadas a sua atividade essencial, a guerra. Entende-se o terror infundido nos demais povos, uma vez que o saque tornou-se a razão de existência das sociedades mbangalas, lideradas por chefes que invocavam para si poderes sobrenaturais.

Cavazzi de Montecúccolo e seus contemporâneos notaram a existência, entre os mbangalas, de um conjunto de regras sociais que definiam a identidade dos membros do grupo, que ele classificava como uma "seita". O nome mais adequado seria sociedade iniciática, uma vez que não era o nascimento, mas a adoção dos indivíduos, que determinava a participação dos kilombos. $\mathrm{O}$ ato essencial da formação da comunidade foi a eliminação das crianças, explicada por diferentes mitos fundadores e preservada num ritual periódico de infanticídio. Por meio deste ritual, atualizava-se a ruptura inicial dos membros do grupo com as matrilinhagens originais, pela abolição da descendência. Os jovens aprisionados, real ou simbolicamente, podiam, por sua vez, ser admitidos no grupo mediante rituais particulares de iniciação. 


\title{
Jagas, Canibalismo e "Guerra Preta": os Mbangalas, entre o mito europeu e as realidades sociais da África Central do século XVII
}

O frei capuchinho teve conhecimento dos mitos de origem dos mbangalas e os reproduziu em sua Istorica descrizione, agregando-lhes valores morais cristãos. Ele recria a cena original do ritual do infanticídio em tom dramático, atribuindo a criação do costume a uma das primeiras líderes mbangala, Musassa, que é lembrada nas tradições orais como Temba Ndumba:

\begin{abstract}
Na presença de todo o povo, fez trazer sua criança e em vez de a acariciar, lançou-a furiosamente num almofariz e, com toda a força do seu cruel instinto, começou a maltratá-la, batendo-lhe com um pau, sem dó e sem compaixão pelos seus gritos. Reduzindo a carne, o sangue e os miolos a uma massa informe, juntou mais umnas raízes, uns pós e umas ervas, e pôs aquela mistura sobre o lume, até ferver e se reduzir à consistência desejada. Depois untou com esta massa todo o corpo e pôs o resto nalguns recipientes. Por essa horrível cerimônia pretendeu que todos a julgassem imortal, invencível e invulnerável (MONTECÚCCOLO, 1965, I, p. 178).
\end{abstract}

Não levando em conta os juízos do narrador agregados à descrição, o que se pode inferir a partir do mito sacrificial é a caracterização do infanticídio como uma forma de acumulação do poder que seria, de outra forma, transmitido à linhagem, num ritual de "fechamento de corpo". A energia da criança, retida no unguento denominado maji-a-samba, era transferida ao que fosse por ele ungido, tornando-se uma fonte de poder sobrenatural. Esta cerimônia sobreviveu de modo residual durante muito tempo entre os mbangalas, e até pelo menos a segunda metade do século XIX a cerimônia de ascenção ao poder dos reis de Kasanje era seguida de um ritual denominado sembamento, ou sambamento, que consistia na execução (real, ou simbólica) de um indivíduo, chamado nicongo, que depois vinha a ser cozinhado junto com a carne de animais e partilhado num banquete coletivo entre o rei e os chefes de linhagens, chamados macotas (CARVALHO, 1898, p. 432) ${ }^{7}$.

Junto com o infanticídio, a antropofagia e os sacrifícios humanos serviram de base para os elementos essenciais das regras de convivência entre os mbangalas. A denominação dessas regras, kesila, kisila ou quijila, provinha da língua kimbundo e significava, literalmente, "proibição". Consistiam em sua maior parte em limitações impostas aos indivíduos e se dividiam, na classificação proposta por Cavazzi de Montecúccolo, em três categorias: domésticas, religiosas e civis. Segundo ele, as primeiras prescreviam a observância de algumas tradições dos antepassados, como a proibição do consumo de carne de porco, de elefante ou de serpente; no segundo grupo 
estavam as prescrições de feiticeiros, chamados nganga ou xinguila, a respeito dos cuidados nas contendas, nas doenças e nos perigos de morte; e no terceiro grupo estavam a proibição de criar filhos do sexo masculino no interior do kilombo, a adoção dos rapazes presos em guerra na comunidade e a prática do canibalismo e dos sacrifícios humanos.

O informante percebia a dimensão sociorreligiosa dessas instituições e, em meio às recorrentes demonstrações de indignação e repugnância, fornece indícios do seu significado para os adeptos das regras do kilombo. Ele sabia que tais rituais, associados a certos objetos, estavam revestidos de autoridade e poder por simbolizar certas conexões com o sobrenatural e com os espíritos dos antepassados (THORNTON, 2008, p. 88-94; THORNTON, 2004, p. 312-354; SOUZA, 2006). Numa passagem, noticia que os xinguila, os portadores dos conhecimentos religiosos tradicionais (portanto, seus concorrentes na esfera do sagrado), monopolizavam certos segredos que conferiam a crença na invencibilidade dos guerreiros: "os xinguila, para ganharem mais, ensinam a quem lhes aprouver uma quantidade de segredos, inventados à toda, e prometem aos doutrinados que nunca poderão ser atingidos, feridos, envenenados ou mortos" (MONTECÚCCOLO, 1965, I, p. 185).

De modo similar, identifica o valor do culto nos ancestrais da comunidade, os defuntos, a quem "preparam cuidadosamente diversas comidas nas covas correspondentes à cabeça dos cadáveres, sacrificando para isso homens e animais", e que o espírito dos defuntos entrava no corpo do xinguila, "manifestando os seus desejos e as suas necessidades" (MONTECÚCCOLO, 1965, I, p. 185-186). É aqui, na articulação entre a crença nos ancestrais e as exigências de uma sociedade altamente militarizada, que se explica o costume da antropofagia e dos sacrifícios humanos. Mas isso não ocorria ao acaso, muito menos com finalidade alimentar. Integrava-se a rituais periódicos que seguiam uma forma e produziam significados muito particulares aos membros do grupo. De resto, a relação entre feitiçaria e canibalismo podia ser observada em diversos povos de língua kikongo e kimbundo, na crença de que determinados feiticeiros ou reis comiam o coração de suas vítimas para adquirir poder, crença transferida para o Novo Mundo pela figura do "branco canibal" (THORTON, 2003; CHILDS, 1960, p. 276).

Os adversários vencidos eram sacrificados por ocasião de rituais funerários. Segundo Cavazzi de Montecúccolo, no dia da cerimônia eles eram coroados com grinaldas, recebiam cumprimentos e obséquios dos presentes, súplicas para que 


\section{Jagas, Canibalismo e "Guerra Preta": os Mbangalas, entre o mito europeu e as realidades sociais da Africa Central do século XVII}

intercedessem pelos vivos, e depois eram executados e devorados. A ingestão de carne humana parece ter sido compreendida como transferência de energia vital, o que explica que aos chefes estivesse reservado o direito de comer o coração dos principais inimigos (MONTECÚCCOLO, 1965, I, p. 184, 195). O costume integra-se aos sistemas de valores dos povos antigos de tradição cultural banto, em que o universo é concebido como impregnado de energia cuja fluência e distribuição motivam os comportamentos, fundam as crenças religiosas, desenvolvem e justificam a magia e impregnam os atos sociais (ALTUNA, 2006, p. 50). Esta crença transparece na passagem abaixo, em que os juízos morais desfavoráveis do capuchinho não obscurecem a identificação do sentido cultural provavelmente compartilhado pelos participantes do sacrifício:

Os jagas, para maior alívio da alma dos finados, depois de sacrificarem homens e animais, penduram os corpos das vítimas com a cabeça para baixo, sobre a campa, e cortando as cabeças, deixam que todo o sangue caia sobre a mesma. Por fim, cortam todos os outros membros para que qualquer resto de sangue seja também derramado. Durante esta supersticiosa cerimônia porém, não cuidam da sede do falecido, mas também na sua própria, pois enchem de sangue algumas taças e bebem-no avidamente (MONTECÚCCOLO, 1965, I, p. 187).

\section{Transformações Sociais}

Levando em conta as divisões internas do segundo livro da Istorica descrizione, em que Cavazzi de Montecúccolo retrata os jagas e seus costumes, pode-se considerar a existência de três partes distintas na tradução do texto aqui utilizada. Na primeira, intitulada "origem e expansão dos jagas", encontra-se a descrição dos costumes antigos, fundadores da comunidade. A segunda, intitulada "crenças e sacrifícios dos jagas", pode ser subdividida em duas, quanto aos temas e à abordagem - a descrição dos costumes contemporâneos ao narrador e, na parte final, uma interpretação das crenças religiosas entre os jagas do Ndongo e de Matamba -, numa espécie de teorização dos poderes atribuídos aos xinguilas e aos rituais e cerimônias rotulados como "idolatria".

Ocorre, entretanto, que, ao coletar as informações e reorganizá-las ao longo do texto, o escritor encontrava-se diante de fenômenos marcados por diferentes temporalidades, entre o surgimento dos mbangalas, no passado, e as modificações introduzidas na estruturação do kilombo no decurso de um século de história. Isto quer dizer que, nesse lapso de tempo, a violência das instituições iniciais foi atenuada por 
rituais novos ou formas de simbolização que restituíram, entre os mbangalas, os vínculos com novas linhagens de chefes ou com novos ancestrais. Cavazzi de Montecúccolo admite, por exemplo, a existência de um ritual particular, denominado quiluvia, realizado em honra dos chefes e senhores renomados, transformados assim em objeto de reverência comunitária. Repetem-se também alusões a um objeto denominado mussete, um cofre de madeira pertencente aos chefes e exibido em momentos solenes, em que ficavam guardados os ossos dos defuntos principais, a quem eram oferecidos cereais. Numa das referências a esse objeto consagrado, o conteúdo do mussete sofre significativa alteração, contém "ídolos embrulhados em panos ou em peles de animais", expostos à "veneração pública" (MONTECÚCCOLO, 1965, I, p. 182; 193; 197; 208; 212). Seria possível entrever, nesse caso, a evolução e refinamento dos cultos rendidos aos ancestrais semidivinizados na figura dos ídolos?

Em outro trecho, cujo acontecimento é datado com maior precisão, o capuchinho informa que, quando entrou no kilombo de Kasanje em 1660, os guerreiros invocavam o espírito de uma entidade chamada Pando, que se manifestou por possessão de um xinguila. Na preparação do sacrifício exigido pelo espírito, a carne de dois indivíduos sacrificados foi misturada ao sorgo, depois, posta a ferver e distribuída aos presentes. Linhas adiante, lembra que os xinguilas matam homens e bebem-lhe o sangue misturado com vinho (MONTECÚCCOLO, 1965, I, p. 208-209). Nos dois casos pode-se observar uma atenuação na descrição do canibalismo pela mistura da carne humana com produtos naturais ou fabricados (sorgo; vinho), provavelmente porque, em contato com outros povos sedentários e agricultores, os mbangalas da segunda metade do século XVII já não viviam exclusivamente da guerra. As modificações daí decorrentes repercutiram em sua reestruturação social, provocando fusões e rearranjos em suas ideias e concepções religiosas, que se mesclaram às dos povos bakongo e mbundo (MONTECÚCCOLO, 1965, I, p. 209).

A evolução social interna produziu rituais novos, mais condizentes com o processo de sedentarização em curso. Daí, a existência de rituais de invocação da chuva, propícios aos ciclos das plantações e colheitas. As próprias práticas do infanticídio ou abandono dos filhos sofreram alterações, vindo a ser substituídas por formas rituais de reintegração das crianças no grupo, de modo a aparentemente não se alterarem os costumes antigos. Essas modificações podem ser encontradas nas descrições deixadas pelos contemporâneos em diferentes momentos de contato com os jagas. Enquanto no início do século XVII, em 1601, Andrew Battell dizia ter assistido à prática do 
infanticídio (RAVENSTEIN, 1910, p. 32-33), nove décadas depois, em 1690, Cadornega informa que as crianças nasciam fora dos limites do kilombo e depois eram reintegradas "como se fora entrado o seu arraial de alguma gente inimiga" (v. 3, p. 222). Tal modificação atesta a recuperação de duas noções fundamentais nas sociedades africanas: a ideia de descendência e a de pertencimento a uma linhagem.

Cavazzi de Montecúccolo assistiu a esses rituais de reintegração das crianças ao seio da comunidade, vigente entre os jagas de Matamba e de Kasanje em 1660. Num dia reservado especialmente para esse fim, na presença do chefe (sembanza), de sua esposa principal (tembanza) e do mussete, os pais das crianças compareciam vestidos e enfeitados para a cerimônia de admissão dos filhos. Todos os presentes, divididos em grupos, fingiam uma batalha, e depois simulavam raptar os sobreviventes do combate, que, na realidade, eram seus filhos. Nas palavras do capuchinho, ao fim da luta simulada e de prolongadas danças:

Saem de algumas moitas predispostas as mães que nelas estavam escondidas, com os meninos, e, mostrando-se preocupadas, com mil gestos vão ao encontro dos maridos, indicando-lhes o lugar em que cada menino está escondido. Então eles correm para lá com os arcos frechados e, descobrindo a criatura, tocam levemente nela com a seta, para demonstrar que não a consideram como filho, mas como preso de guerra, e que, portanto, a lei não fica violada. Depois, usando uma perna de galinha, untam a criança com aquele ungüento no peito, nos lombos e no braço direito. Desta maneira, os pequenos são julgados purificados e podem ser introduzidos pelas mães no quilombo na noite seguinte (MONTECÚCCOLO, 1965, I, p. 182).

O tempo do canibalismo e do infanticídio dos mbangala havia passado.

\section{Considerações Finais}

Para finalizar, cumpre reconhecer que uma avaliação ponderada das informações fornecidas por Cavazzi de Montecúccolo deve levar em conta alguns aspectos que, em nosso entender, the conferem uma posição mais justa e mais equilibrada como testemunho direto das realidades sociais da África central na segunda metade do século XVII.

Em que pesem as deformações culturais ou interpretações parciais, francamente desfavoráveis aos povos que ele pretendeu retratar devido às limitações impostas pela lente euro-cristã, ele esteve durante anos entre os mbangalas e, além do testemunho 
ocular, teve o privilégio de recolher informação direta dos sujeitos a quem esperava converter. Por tudo isso, é preciso submeter a uma avaliação severa todas as informações por ele fornecidas, com identificação de prováveis interferências culturais em sua enunciação e relativização do grau de objetividade que apresentam. Mas nunca rechaçar de todo o seu valor como testemunho histórico, devido à posição privilegiada do autor no seio da sociedade que retratou. O melhor, parece, é tentar detectar os substratos etnográficos que apresenta, reinserindo-os, na medida do possível, no contexto em que efetivamente existiram.

Por outro lado, o resgate do papel dos mbangalas no contexto histórico da África centro-ocidental dos séculos XVI-XVII contribui positivamente para o aprofundamento de nossos conhecimentos a respeito dos diferentes processos de transformação social responsáveis pelo enfraquecimento e perda de influência do reino de Ndongo. Sua entrada na área mbundo, através do rio Kwanza, ocorreu mais ou menos na mesma época da entrada em cena dos portugueses. A articulação entre esses dois grupos de estrangeiros teve peso decisivo na redução da autoridade dos governantes tradicionais mbundo, os ngola, e no aparecimento de um conjunto novo de estados africanos, como Matamba e Kasanje, que, junto com o estado português de Angola, participaram ativamente do tráfico transatlântico de escravos.

\section{Referências Bibliográficas}

\section{Fontes Primárias}

BRÁSIO (ed). Monumenta Missionaria Africana. Lisboa: Agência Geral do Ultramar; Academia Portuguesa da História, 1953-1981, 15 vols.

CADORNEGA, A. O. História Geral das Guerras angolanas. Lisboa: Agência Geral do Ultramar, 1972, 3 vols.

CORDEIRO, L. (ed). Terras e minas africanas segundo Baltasar Rebelo de Aragão (1593-1630.). In: Questões histórico-coloniais. Lisboa: Ministério das Colônias, 1935, v. 1, p. $215-244$.

CUOQ, J. M. (trad). Recueil des sources arabes concernant l'Afrique Occidentale du VIII au XVI siècle (Bilad al-Sudan). Paris: CNRS, 1985.

FELNER, A. A. (ed). Livro de feitoria de Manoel Pereira, 16/08/1629. In: Apontamentos sobre a ocupação e início do estabelecimento dos portugueses no 
Congo, Angola e Benguela, tirado de documentos históricos. Coimbra: Imprensa da Universidade, 1933.

HEINTZE, B (ed). Fontes para a História de Angola no século XVII, I. Memórias, relações e outros manuscritos da colectânea documental de Fernão de Souza (16221635). Stuttgart: Franz Steiner Verlag Wiesbaden, 1985.

LOPES, D.; PIGAFETTA, F. Relação do reino de Congo e das terras circunvizinhas. Lisboa: Agência Geral do Ultramar, 1951

MONTECÚCCOLO, J. A. C. Descrição histórica dos três reinos do Congo, Matamba e Angola. Trad. de Graciano Maria de Leguzzano. Lisboa: Junta de Investigações do Ultramar, 1965, tomos I-II.

RAVENSTEIN, E. G. (ed). The strange adventures of Andrew Battell of Leigh, in Angola and adjoining regions. Londres: Hakluyt Society, 1910.

\section{Bibliografia}

ALBANO, M. Cavazzi, conselheiro diplomático da rainha Nzinga. In: MATA, I. (org). A Rainha Nzinga Mbandi: História, memória e mito. Lisboa: Edições Colibri, 2012, p. 217-220.

ALINA. E.. The zimba, the portuguese, and others cannibals in late sixteenth century southeast Africa. Journal of Southern African Studies, v. 37 n. 2, 2011, p. 211-227.

ALMEIDA, C. J. D. A representação do africano na literatura missionária sobre o Reino do Kongo e Angola. 1997. Dissertação (Mestrado) - Faculdade de Ciências Sociais e Humanas - Universidade Nova de Lisboa, Lisboa, 1997.

ALTUNA, R. R. A. Cultura tradicional bantu. 2. ed. Luanda: Ed. Paulinas, 2006.

AVELOT, R. Les grand mouvements des peuples en Afrique: Jaga et Zimba. Bulletin de Geographie Historique et Descriptive (Paris), n. 1-2, 1912, p. 76-216.

BIRMinghaM, D. A conquista portuguesa de Angola. Porto: A Regra do Jogo, 1974.

BONTIK, F. Un mausolée pour les jagas. Cahiers d'Études Africaines, v. 20 n. 79, 1980, p. 387-389.

CABRAL, J. P. Galvão na terra dos canibais: a constituição emocional do poder colonial. In: BASTOS, C. (org). Trânsitos coloniais - diálogos críticos luso-brasileiros. Campinas: Ed. Unicamp, 2007, p. 81-104.

CARVAlHO, H. A. D. O jagado de Cassange - Província de Angola. Lisboa: Tipographia de Cristovão Augusto Rodrigues, 1898. 
CHILDS, G. M. The peoples of Angola in the seventeenth century according to Cadornega. Journal of African History (Cambridge), v. 1 n. 2, 1960, p. 271-279.

CORREA, S. M. S. A antropofagia na África equatorial: etno-história e a realidade do(s) discurso(s) sobre o real. Afro-Asia (Salvador), n. 37, 2008, p. 9-41.

CURTO, D. R. Do Reino à África - formas dos projetos coloniais para Angola em inícios do século XVII. In: FURTADO, J. F. (org). Sons, formas, cores e movimentos de modernidade atlântica: Europa, Américas e África. São Paulo: Annablume, 2008, p. 187-217.

DEMARET, M. M.. Portugueses e africanos em Angola no século XVII: problemas de representação e de comunicação a partir da História Geral das Guerras Angolanas. In: RODRIGUES, J. D.; RODRIGUES, C. (orgs). Representações de África e dos africanos na história e cultura: séculos XV a XXI. Ponta Delgada: Universidade dos Açores; Lisboa: Centro de História de Além Mar - FSCH-UNL, 2011, p. 107-130

DIAS, J.. Uma fonte inexplorada para a história de Angola no século XVII: a colectânea de Fernão de Souza. Revista Internacional de Estudos Africanos (IICT-Lisboa), vol. 3, 1985, p. 221-224.

FONSECA, M. B. Nzinga Mbandi e as guerras de resistência em Angola. Século XVII. 2012. Dissertação (Mestrado em História) - FFLCH, Universidade de São Paulo, São Paulo, 2012.

FONSECA. M. B. Rainha nzinga mbandi, imbangalas e portugueses: as guerras nos kilombos de angola no século XVII. Cadernos de Pesquisa Cdhis (Uberlândia), v. 23 n. 2, 2010, p. 391-415.

GONÇALVES, A. C. A história revisitada do Kongo e de Angola. Lisboa: Editorial Estampa, 2005.

GONÇALVES, R. A. África indômita: missionários capuchinhos no reino do Congo (século XVII). 2008. Dissertação. (Mestrado em História) - FFLCH, Universidade de São Paulo, São Paulo, 2008.

HEINTZE, B. Angola nas garras do tráfico de escravos: as guerras do Ndongo (16111630). Revista Internacional de Estudos Africanos (IICT - Lisboa), n ${ }^{\circ} 1,1981$, p. 1159.

HEINTZE, B. Contra as teorias simplificadoras: o 'canibalismo' na antropologia e história de Angola. In: SANCHES, M. R. (org). Portugal não é um país pequeno: contar o império na pós-colonialidade. Lisboa: Livros Cotovia, 2006, p. 216-228.

HENRIQUES, I. C. A invenção da antropofagia africana. In: Os pilares da diferença: relações Portugal-África, séculos XV-XX. Lisboa: Caleidoscópío, 2004, p. 225-246.

HILTON, A. The jaga reconsidered. Journal of African History, v. 22 n. 2, 1981, p. 191-202. 
HORTA, J. S.. Primeiros olhares sobre o africano do Sara ocidental à Serra Leoa (meados do século XV - inícios do século XVI). In: FERRONHA, A. L. (dir.). O confronto do olhar: o encontro dos povos na época das navegações portuguesas. Lisboa: Ed. Caminho, 1991, p. 73-125.

MATA, I. (org). A Rainha Nzinga Mbandi: História, memória e mito. Lisboa: Edições Colibri, 2012.

MATTOS, D. M.. Entre Deus e o Demônio: perspectivas de análise da obra de Cavazzi de Montecúccolo e da ação missionária na África à luz das expansões ultramarinas européias. História: Imagens e Narrativas, n. 13, 2011. Disponível em: http://www.historiaimagem.com.br/edicao13outubro2011/deus-demo.pdf

MILLER, J.. Requiem for the “jaga”. Cahiers d'Études Africaines, v. 13 n. 49, 1973, p. 121-149.

MILLER, J.. Thanatopsis. Cahiers d'Études Africaines, v. 18 n. 68-70, 1978, p. 229231.

MILLER, J. C. Poder político e parentesco: os antigos estados mbundu em Angola. Luanda: Arquivo Histórico Nacional, 1995.

NSONDÉ, J.. Christianisme et religion traditionelle en pays koongo aux XVII-XVIII siècles. Cahiers d'Études Africaines (Paris), v. 32 n. 128, 1992, p. 705-711.

NSONDÉ, J. Langues, culture et histoire koongo aux XVII et XVIII siècles. Paris: Harmattan, 1995.

OLIVEIRA, I. S. Semelhanças e diferenças na escrita da história da África centroocidental no século XVII: os casos de Cadornega e Cavazzi de Montecúccolo. Cadernos de Pesquisa do Cdhis (Uberlândia), v. 23 n. 2, 2010, p. 416-425.

PARREIRA, A. Economia e sociedade em Angola na época da Rainha Jinga (século XVII). Lisboa: Estampa, 1990.

PINTO, P. J. S. Em torno de um problema da identidade. Os "jagas" na história do Congo e Angola. Mare Liberum (UNL - Lisboa), , n. 18-19, 1999-2000, p. 193-243.

RANDLESS, W. G. L.. La fondation de la mission des capucins au royaume du Congo (1648) (Jean-François de Roma, O.F.M.). Annales E.S.C. (Paris), vol. 23 n. 1, 1968, p. 225-227.

RANDLESS, W. G. L. L'ancien royaume du Congo, des origenes a la fin du XIX siécle. Paris: Mouton \& co, 1968.

RICARD, R. Misiones Capuchinas en Africa. Bulletin Hispanique, vol. 60-4, 1958, p. 557-559. 
SOUZA, M. M. Religiões tradicionais e catequese na África central, século XVII. Phronésis (Campinas), vol. 8 n. 1, 2006, p. 121-138.

THORNTON, J. The kingdom of Kongo, ca. 1390-1678. The development of an african social formation. Cahiers d'Études Africaines (Paris), vol. 22 n. 87-88, 1982, p. 325342.

THORNTON, J. A resurrection for the jaga. Cahiers d'Études Africaines, v. 18 n. 6970, 1978, p. 223-227.

THORNTON, J. Cannibals, witches, and slave traders in the Atlantic world. The William and Mary Quarterly (Williamsburg, Virginia), vol. 60 n. 2, 2003, p. 273-294.

THORNTON, J. A África e os africanos na formação do mundo atlântico. Rio de Janeiro: Elsevier, 2004.

THORNTON, J. Religião e vida cerimonial no congo e áreas Umbundo, de 1500 a 1700. In: HEYWOOD, L. M. (org). Diáspora negra no Brasil. São Paulo: Contexto, 2008, p. 81-100.

VANSINA, J. Les anciens royaumes de la savane: les etats des savanes méridionales de l'Afrique centrale des origines à l'occupation coloniale. Léopoldville (Congo): Institut de Recherches Economiques et Sociales, 1965.

VELLUT, J. L. Le royaume de Cassange et les reseaux luso-africains (ca. 1750-1810). Cahiers d'Études Africains, v. 15 n. 57, 1975, p. 117-136

WOORTMANN, K.. O selvagem e a Gesta Dei: história e alteridade no pensamento medieval. Revista Brasileira de História (São Paulo), vol. 25 n. 50, 2005, p. 259-314.

\footnotetext{
Notas

${ }^{1} \mathrm{Na}$ interpretação de GONÇALVES (2005), tais medidas alteraram significativamente o modelo políticosocial até então vigente no Congo, criando uma nova realidade política e introduzindo noções inexistentes até então, sobretudo: a ideia de uma territorialidade associada a sua autoridade como governante; a noção de uma sucessão dinástica em linha direta, por descendência em linha patrilinear e patrilocal; e a formação de uma corte, a unidade político-cultural a partir do modelo fornecido pelo cristianismo.

2 Neste texto, o designativo Angola será utilizado para se referir à área efetiva de ocupação portuguesa até meados do século XVII, situada sobretudo entre as fortalezas de São Paulo de Luanda e Massangano e praticamente limitada ao litoral, que coexistiu com vários estados na área mbundo e ovimbundo.

3 Entre diversos documentos, ver a Relação de António Diniz, de 1622 (BRÁSIO, v. 7, p. 70), em que o funcionário da coroa luso-espanhola defende a legitimidade da cobrança de impostos sobre o que se pescasse anualmente na Ilha de Luanda em nome do rei de Portugal, baseando-se numa suposta concessão desse direito por Álvaro I, "desde o tempo que lhe resgatou o rejno, que lho tinhão tomado os jagas".

$4 \mathrm{Na}$ África central do século XVII, este termo de origem kimbundo tinha duas acepções, oscilantes e intercambiáveis. Em primeiro lugar, designava um arraial, um acampamento defensivo mais ou menos permanente, com finalidade militar. Em segundo lugar, designava a ideia de ajuntamento, de união entre certos indivíduos, amplamente difundida no Congo, Matamba, Ndongo e nos estados ovimbundo do atual planalto central angolano, onde provavelmente teve sua origem (PARREIRA, 1990, p. 153).
} 
5 No princípio da terceira parte da obra (CADORNEGA, 1972, v. 3, p. 222-230), onde descreve em pormenor as instituições do que viria a se chamar jagado de Kasanje, menciona alguns costumes e ritos dos jagas, indicando também de modo vago e genérico o hábito do consumo de carne humana.

6 Segundo Joseph Miller (1995, p. 163), nas tradições orais a cerimônia de matar o(a) "fillho(a)" simbolizava o poder absoluto do governante sobre os seus súditos, pois os "fillhos", na narrativa, representam os súditos de um chefe político, em contraste com os seus parentes, que são sempre descritos como "sobrinhos e sobrinhas". Num sentido mais literal, porém, a matança dos filhos, quando praticada por toda uma população, tornava-se um meio de abolir as linhagens, uma vez que o assassinato dos filhos (ou a negação do significado social de um nascimento físico) tinha sobre os grupos de filiação o mesmo efeito estrutural que a proibição do seu nascimento".

7 Note-se que, nas antigas tradições mbundo, os termos samba ou semba estavam relacionados aos principais títulos dos governantes do kilombo, sambanza para os maridos e tembanza para as esposas.

Recebido em março/2013

Aprovado em maio/2013 